\title{
Development and characterization of microsatellite markers in Gaultheria pumila Lf. (Ericaceae)
}

\author{
Rolando Garcia-Gonzales ${ }^{*}$ (D) , José Pico-Mendoza ${ }^{2,3,4^{*}}$, Karla Quiroz ${ }^{3 *}$, Basilio Carrasco ${ }^{5}$, Pablo Cáceres ${ }^{3}$, \\ Borys Chong-Perez ${ }^{1}$, Hugo Pino ${ }^{3}$, Marjorie Seiltgens ${ }^{1,3}$, Eglis Greck ${ }^{3}$ and Peter D. S. Caligari6
}

\begin{abstract}
Background: Polymorphic microsatellite markers were developed for Gaultheria pumila (Ericaceae) to evaluate genetic diversity and population structure within its native range in Chile. This is a very important Ericaceae endemic to Chile with a large commercial potential. Its resistance to different abiotic conditions makes it a valuable target for genetic improvement.
\end{abstract}

Results: Ten polymorphic simple sequence repeat (SSR) loci were isolated from Gaultheria pumila using newgeneration 454 FLX Titanium pyrosequencing technology. The mean number of alleles per locus ranged from 2 to 4. Observed and expected heterozygosity ranged from 0.00 to 1.0 and 0.00 to 0.64 , respectively.

Conclusions: From 10 SSR markers developed for G. pumila, 9 markers are promising candidates for analyzing genetic variation within or between natural populations of $G$. pumila and other species from the same genus.

Keywords: Microsatellite, Pyrosequencing, Chilean berry, Gaultheria pumila

\section{Background}

The Gaultheria genus belongs to the Ericaceae family and is adapted to tropical and temperate conditions. In Chile, all of these species are commonly known as "chaura" or "mutilla del zorro" [1]. Gaultheria pumila is one of the most important species of this genus in Chile, regarding population size. In the wild, it is considered as a primary colonizing plant [2], capable of associating with symbiotic mycorrhizas [3]. The species shows a high degree of phenotypic diversity and even a botanic variety has been identified (Gaultheria pumila var. leucocarpa). It is an interesting species for domestication since it has shown

\footnotetext{
*Correspondence: biotecnos.rg@gmail.com; pepinpico@gmail.com; jwpico@utm.edu.ec; kquiroz@ucm.cl

${ }^{1}$ Sociedad de Investigación y Servicios, BioTECNOS Ltda, 49 1⁄2 Oriente, 2385, Parque del Sol, Talca, Chile

${ }^{2}$ Facultad de Ingeniería Agronómica, Universidad Técnica de Manabí, Portoviejo, Manabí, Ecuador

${ }^{3}$ Centro de Biotecnología de los Recursos Naturales, Departamento de Ciencias Forestales, Universidad Católica del Maule, Campus San Miguel, Av. San Miguel 3605, Casilla 617, Talca, Chile

Full list of author information is available at the end of the article
}

a high level of phenotypic variability and high levels of polyphenols and anthocyanins $[4,5]$. However, the lack of basic knowledge of agronomically important traits as well its genetic variability are serious limitations to its domestication process for its agronomic and commercial use. For this reason, the aim of this study was to develop a set of polymorphic microsatellite markers to be used as a tool to assess the diversity and genetic structure of $G$. pumila and other species of the Gaultheria genus.

\section{Methods}

In order to carry out complete sequencing, four samples of G. pumila were collected in two places. The Villarrica volcano in Región de la Araucanía, Chile, S: $39^{\circ} 21^{\prime} 570$, W: 71'57'865 (El Playón sector), and near the Puyehue volcano, in Región de Los Lagos, Chile, S: $40^{\circ} 41^{\prime} 484$, W: $72^{\circ} 32^{\prime} 719$ (Orilla del Río sector). All the samples from the protected natural areas were collected under the authorization of the regulatory Chilean Agency, Corporación Nacional Forestal (CONAF). 
The samples for sequencing were selected according to fruit color: red, pink and white. Total genomic DNA of G. pumila was extracted from young leaves with a modified CTAB (cetyltrimethylammonium bromide) method [6]. The quality and quantity of isolated DNA was determined using a Nanodrop and agarose gel electrophoresis. The library preparation and shotgun pyrosequencing of $5 \mu \mathrm{g}$ DNA aliquot on a 454 GS-FLX instrument (Roche Applied Science, MACROGEN, Ltd. Seoul, South Korea) was prepared with the kit of Titanium Pico Titer Plate (Roche Diagnostics), following the manufacturer's protocols.

A total of 164,000 sequences were read, with an average length of $417 \mathrm{bp}$, which were generated by three independent runs. The sequences were assembled using the software GS De Novo Assembler v2.9 (http://genso ft.pasteur.fr/docs/454_DataAnalysis/2.9/USM-00058 .09_454SeqSys_SWManual-v2.9_PartC.pdf).

The MSATCOMANDER (http://code.google.com/p/ msatcommander/) software for locating microsatellites was used. MSATCOMMANDER is a program written to locate microsatellite repeats within fasta-formatted sequences or consensus files. MSATCOMMANDER will search for all di-, tri-, tetra-, penta, and hexa-nucleotide repeats. The search parameters were: mononucleotide repeat length: 10 , dinucleotide repeat length:
6 , trinucleotide repeat length: 4 , tetranucleotide repeat length: 4, pentanucleotide repeat length: 4 , and hexanucleotide repeat length: 4 .

The primers were designed using the software PRIMER 3 [7]. The PCR fragment amplification and validation of selected SSRs were performed following the method developed by [8] which uses three primers: a forward primer with an M13 (-21) tail at its $5^{\prime}$ end, a normal reverse primer and the universal M13 (-21) primer labeled with either 6-FAM, VIC, PET or NED fluorochromes. The microsatellite information and GenBank accession numbers are listed in Table 1. PCR reactions were performed in a $20 \mu \mathrm{L}$ reaction mixture with $10 \mathrm{ng}$ templates DNA, $0.15 \mathrm{mM}$ of each dNTP; $1 \times$ Taq polymerase reaction buffer; $1.5 \mathrm{mM} \mathrm{MgCl} ; 0.025 \mu \mathrm{M}$ forward primer; $0.1 \mu \mathrm{M}$ reverse primer; $0.1 \mu \mathrm{M}$ M13 primer and $0.35 \mathrm{U}$ Taq DNA polymerase.

PCR amplifications were performed in an Applied Biosystems Veriti (Life Technologies), under the following conditions: initial denaturation at $94{ }^{\circ} \mathrm{C}$ for $5 \mathrm{~min} ; 30$ cycles of $30 \mathrm{~s}(\mathrm{~s})$ at $94{ }^{\circ} \mathrm{C}$, annealing temperature specific to each primer pair for $45 \mathrm{~s}$, extension at $72{ }^{\circ} \mathrm{C}$ for $45 \mathrm{~s}$, followed by 8 cycles of $30 \mathrm{~s}$ at $94{ }^{\circ} \mathrm{C}$, annealing at $53{ }^{\circ} \mathrm{C}$ for $45 \mathrm{~s}$, extension at $72{ }^{\circ} \mathrm{C}$ for $45 \mathrm{~s}$ and a final extension at $72{ }^{\circ} \mathrm{C}$ for $30 \mathrm{~min}$. The annealing temperature $\left({ }^{\circ} \mathrm{C}\right)$ requirements of primers are specified in Table 1.

Table 1 Characteristics of 10 microsatellite loci and primer pair's development for G. pumila

\begin{tabular}{|c|c|c|c|c|c|c|c|}
\hline Locus & Primer sequences $\left(5^{\prime}-3^{\prime}\right)$ & Products size & Repeat motif & size (bp) & Dye & $\mathrm{Ta}\left({ }^{\circ} \mathrm{C}\right)$ & GenBank \\
\hline \multirow[t]{2}{*}{ GP.7 } & F: CGCATTCACTCACCCTCTCA & 309 & $(\mathrm{ACTC}) \wedge 4$ & 360 & FAM & 52.1 & KX719822 \\
\hline & R:TGGTTGGTGAAGGCTTTGGA & & & & & & \\
\hline \multirow[t]{2}{*}{ GP.9 } & F: ACCCGCTCTAGATCCTCTCT & 321 & $(T)^{\wedge} 10$ & $378-380$ & FAM & 60.5 & KX719823 \\
\hline & R: AGGGGGAGTAATCAAGCCTCT & & & & & & \\
\hline \multirow[t]{2}{*}{ GP.10 } & F: GGGTACGGCGTAGTGGTAAT & 269 & $(\mathrm{AT}) \wedge 8$ & $323-327$ & $\mathrm{VIC}$ & 60.5 & KX719824 \\
\hline & R:TCGTACAAAACCGCCCTCAA & & & & & & \\
\hline \multirow[t]{2}{*}{ GP.12 } & F: AGGATTATAGAGAGCCAGGTGGA & 138 & $(\mathrm{CTT}) \wedge 4$ & 198-201 & NED & 52.1 & KX719825 \\
\hline & R:CAGAAGACGAAATCGAAGCCG & & & & & & \\
\hline \multirow[t]{2}{*}{ GP.13 } & F: AGAGTAAGAGCTCTCTTCCGA & 248 & $(\mathrm{ATT}) \wedge 4$ & $161-278$ & NED & 52.1 & KX719826 \\
\hline & R: GCAGACTCGAATCGGCAGTA & & & & & & \\
\hline \multirow[t]{2}{*}{ GP.14 } & F: GCATAGCCCGGTTGTCAAAC & 174 & $(A C G C) \wedge 4$ & $196-228$ & PET & 52.1 & KX719827 \\
\hline & R: ACCGAAAGATCCGACCATCG & & & & & & \\
\hline \multirow[t]{2}{*}{ GP.15 } & F: GGGCTGCTGCTCAATCAATT & 287 & $(\mathrm{~T}) \wedge 10$ & $347-351$ & $\mathrm{VIC}$ & 52.1 & KX719828 \\
\hline & R: ACCCGCTTCAAGTCATGATGA & & & & & & \\
\hline \multirow[t]{2}{*}{ GP.16 } & F: GCTATTTCTAGGGCCGGACC & 218 & $(\mathrm{AT}) \wedge 6$ & $281-283$ & FAM & 52.1 & KX719829 \\
\hline & R: GCACAATACATAGATTCTGGATCGA & & & & & & \\
\hline \multirow[t]{2}{*}{ GP.17 } & F: GAGAGAAATCCACCAGGGCA & 145 & $(T) \wedge 10$ & $202-205$ & VIC & 60.5 & KX719830 \\
\hline & R: CAAGCGGACGACGTATACGA & & & & & & \\
\hline \multirow[t]{2}{*}{ GP.18 } & F: ACCGAAAGATCCGACCATCG & 174 & $(\mathrm{GCGT}) \wedge 4$ & $192-228$ & PET & 52.1 & KX719831 \\
\hline & R: GCATAGCCCGGTTGTCAAAC & & & & & & \\
\hline
\end{tabular}


PCR products were resolved as following: $2 \mu \mathrm{L}$ of PCR products were mixed with $10 \mu \mathrm{L}$ HiDi formamide (Applied Biosystems) and $0.2 \mu \mathrm{L}$ GeneScan 500LIZ size standard (Life Technologies, Foster City, CA) and separated by capillary electrophoresis on an ABI 3130xl Prism Genetic Analyzer with POP-7 polymer (Life Technologies, Foster City, CA) in the Genetic Resources Unit, La Platina-INIA, Chile. Allele sizes were automatically calculated with GeneMapper software v4.0 and manually checked.

Three populations of G. pumila were selected to evaluate the variability in the isolated loci: Región de la Araucanía, (Villarrica volcano, $\mathrm{n}=10$ ); Región de los Lagos, (Puyehue volcano, $\mathrm{n}=10$ ); Región de Magallanes y la Antártica chilena (Punta Arenas, $\mathrm{n}=10$ ). Genetic parameters such as observed number of alleles $(\mathrm{Na})$ and observed and expected heterozygosity $(\mathrm{Ho}-\mathrm{He})$ were estimated with PopGene [9]. The inbreeding coefficient $\left(F_{I S}\right)[10]$ was determined using Genetix [11]. Deviation from the Hardy-Weinberg equilibrium was determined with GENEPOP v 4.2 [12] (Table 2). The presence of null alleles was checked using MICRO-CHECKER version 2.2.3 [13].

In addition, cross-amplification was tested in two other species, Gaultheria mucronata and Gaultheria caespitosa. PCR reactions and electrophoresis were performed according to the conditions described above.

\section{Results}

Primers were considered successful when one clear distinct band was detected on $2 \%$ agarose gel. Primers were designed with flanking repeat lengths of at least 10, 6 and 4 for mononucleotides, dinucleotides, and higher core repeats, respectively. Mononuclotide-containing repeats were the most frequent (59\%), followed by dinucleotides $(23 \%)$, trinucleotides (12\%), tetranucleotides (3\%) and pentanucleotides (2\%).

Seventeen SSRs were tested and they included primers for four mononucleotides, five dinucleotides, four trinucleotides, three tetranucleotides, and one pentanucleotide. The first test consisted of selecting the best SSRs that showed amplification in a $2 \%$ agarose gel after electrophoresis. Ten SSRs were selected for further development and analysis. From these microsatellite loci, nine were variable and polymorphic between populations.

The microsatellite GP.7 was inconsistent in different tested condition, and it was not included further. The mean number of alleles per locus ranged from 1 to 4 , with an average of 1.96. Observed and expected heterozygosity ranged from 0.00 to 1.0 and 0.00 to 0.67 , respectively. In addition, three microsatellites loci GP.12, GP.13, GP.17 exhibited significant deviation from HardyWeinberg equilibrium, for the Puyehue population. In the Villarrica population GP.14 was monomorphic, while the loci GP.9, GP.10, GP. 12, GP.13 and GP.18 had no significant deviations. In Punta Arenas, four loci (GP.9, GP.10, GP.12 and GP.15) did not show significant deviations from HWE. Such deviations can be due to the small sample size, selfing, or to the substructure of the populations. Additionally, after visualization of the PCR products for each loci by gel electrophoresis, it was found that out of 10 SSR loci, 5 showed cross amplification in G. mucronata (GP.14, GP.15, GP.16, GP.17 and GP.18) and 6 G. caespitosa (GP.9, GP.13, GP.14, GP.15, GP.16 and GP.18) (Table 2). This suggests that the markers could be useful

Table 2 Estimated genetic parameters and Hardy-Weinberg test results in 10 microsatellites loci in three wild populations of G. pumila

\begin{tabular}{|c|c|c|c|c|c|c|c|c|c|c|c|c|c|c|}
\hline \multirow[t]{2}{*}{ Locus } & \multicolumn{4}{|c|}{ Puyehue volcano $(n=10)$} & \multicolumn{4}{|c|}{ Villarrica volcano $(n=10)$} & \multicolumn{4}{|c|}{ P. Arenas $(n=10)$} & \multicolumn{2}{|c|}{ Cross-amplification } \\
\hline & $\mathrm{Na}$ & Ho & $\mathrm{He}$ & Fis & $\mathrm{Na}$ & Ho & $\mathrm{He}$ & Fis & $\mathrm{Na}$ & Ho & $\mathrm{He}$ & Fis & G. mucronata & G. caespitosa \\
\hline GP.7 & 1 & 0.00 & 0.00 & NA & 1 & 0.00 & 0.00 & NA & 1 & 0.00 & 0.00 & NA & - & - \\
\hline GP.9 & 1 & 0.00 & 0.00 & -0.24 & 2 & 0.20 & $0.19^{*}$ & -0.34 & 2 & 0.56 & 0.42 & $-0.06^{*}$ & - & + \\
\hline GP.10 & 2 & 0.30 & 0.27 & -0.27 & 3 & 0.67 & $0.50^{*}$ & -0.10 & 2 & 0.22 & 0.21 & $-0.27^{*}$ & - & - \\
\hline GP.12 & 2 & 0.00 & $0.18^{*}$ & 1.00 & 2 & 0.00 & $0.19^{*}$ & 1.00 & 2 & 0.00 & $0.19^{*}$ & $1.00^{*}$ & - & - \\
\hline GP.13 & 2 & 1.00 & $0.53^{*}$ & -0.46 & 4 & 0.60 & $0.59^{*}$ & -1.00 & 2 & 1.00 & $0.53^{*}$ & -0.46 & - & + \\
\hline GP.14 & 2 & 0.10 & 0.10 & -0.00 & 1 & 0.00 & 0.00 & 0.00 & 1 & 0.00 & 0.00 & 0.00 & + & + \\
\hline GP.15 & 3 & 0.70 & 0.67 & 0.45 & 3 & 0.22 & 0.52 & 0.13 & 3 & 0.40 & 0.58 & $0.22^{*}$ & + & + \\
\hline GP.16 & 1 & 0.00 & 0.00 & 1 & 2 & 0.00 & 0.34 & 1.00 & 2 & 0.00 & $0.51^{*}$ & -1.00 & + & + \\
\hline GP.17 & 2 & 1.00 & $0.53^{*}$ & 0.70 & 2 & 1.00 & 0.53 & -1.00 & 2 & 1.00 & $0.53^{*}$ & 0.49 & + & - \\
\hline GP.18 & 2 & 0.10 & 0.10 & 0.13 & 3 & 0.10 & $0.28^{*}$ & -0.03 & 1 & 0.00 & 0.00 & 0.10 & + & + \\
\hline
\end{tabular}

+, successful PCR amplification; -, unsuccessful PCR amplification

Na number of alleles, Ho observed heterozygosity, He expected heterozygosity, Fis fixation index

*Significant deviation from Hardy-Weinberg equilibrium $(P<0.05)$ 
in carrying out studies of genetic diversity in other Gaultheria species.

\section{Conclusions}

Nine microsatellites primer pairs were developed and proved to be polymorphic in three populations of $G$. pumila. These SSRs will be useful for future studies of population structure and assessment of diversity in this species. Also, these findings provide a basis for starting a domestication program for this species, as well as other related species in the Ericaceae family. Further research will be needed to find new SSR microsatellite markers and test them among G. pumila and other species from this genus.

\section{Abbreviations}

CONAF: Corporación Nacional Forestal; CTAB: cetyltrimethylammonium bromide; SSR: simple sequence repeat; PCR: polymerase chain reaction.

\section{Authors' contributions}

RGG led this investigation; JP and RGG, planned and analyzed the raw data as well administered the funds of this research; MS, HP, BCh and EG, performed all the sampling and field work; KQ, BC and PDSC contributed with the statistical and genetical analysis; JP, PC, BCh and RGG performed the laboratory work and sampling processes. All authors read and approved the final manuscript.

\section{Author details}

${ }^{1}$ Sociedad de Investigación y Servicios, BioTECNOS Ltda, 49 1⁄2 Oriente, 2385, Parque del Sol, Talca, Chile. ${ }^{2}$ Facultad de Ingeniería Agronómica, Universidad Técnica de Manabí, Portoviejo, Manabí, Ecuador. ${ }^{3}$ Centro de Biotecnología de los Recursos Naturales, Departamento de Ciencias Forestales, Universidad Católica del Maule, Campus San Miguel, Av. San Miguel 3605, Casilla 617,

Talca, Chile. ${ }^{4}$ Facultad de Ciencias Agrarias, Universidad de Talca, Talca, Chile.

${ }^{5}$ Facultad de Agronomía, Pontificia Universidad Católica de Chile, Avenida

Vicuña Mackenna 4860, Macul, Santiago de Chile, Chile. ${ }^{6}$ Verdant BioScience

Pte. Ltda, 18, Duxton Hill, Singapore 089601, Singapore.

\section{Acknowledgements}

The authors would like to thank the Ecuadorian Government (Senescyt) and the Facultad de Agronomía of the Universidad Técnica de Manabí for the scholarship to José Pico Mendoza. The authors thank the Corporación Nacional Forestal for the support and authorization to access the protected natural areas where the study was developed.

\section{Competing interests}

The authors declare that they have no competing interests.

\section{Availability of data and materials}

The authors declare that all the raw data and materials can be accessed from the uploaded files accompanying this submission.
Ethics approval and consent to participate Not applicable.

\section{Funding}

We are grateful to Gobierno Regional del Maule for supporting this research through the project Laboratorio Regional de Biotecnologías Aplicadas (VITOTRECH II-FIC-BIC 30.136.372-0). This research was also partially supported by institutional funds of the Company Sociedad de Investigación y Servicios BioTECNOS Ltda., from Chile.

\section{Publisher's Note}

Springer Nature remains neutral with regard to jurisdictional claims in published maps and institutional affiliations.

Received: 1 August 2017 Accepted: 19 October 2018

Published online: 01 November 2018
References

1. Teillier S, Escobar F. Revisión del género Gaultheria L. (Ericaceae) en Chile. Gayana Botánica. 2013;70(1):136-53.

2. Luteyn JL. Diversity, adaptation, and endemism in neotropical Ericaceae: biogeographical patterns in the Vaccinieae. Bot Rev. 2002;68(1):55-87.

3. Medina J, Davinson F, Carrillo R, Rodriguez M. Simbiosis micorrícica presente en Nothofagus dombeyi (Mirb.) Oerst y Gaultheria pumila (L. fil) Middleton. Especies Colonizadoras de Escoriales Volcanicos en la Region de la Araucanía, Chile. In: I Congr. Nac. Conserv. la Biodivers. a través su uso, 23 al 25 Noviembre 2009, Sucre Boliv; 2009. p. 1-10.

4. Middleton DJ. A chemotaxonomic survey of flavonoids and simple phenols in the leaves of Gaultheria L. and related genera (Ericaceae). Bot Linn Soc. 1992;110(4):313-24.

5. Villagra $\mathrm{E}$, et al. Morphometric and phytochemical characterization of chaura fruits (Gaultheria pumila): a native Chilean berry with commercial potential. Biol Res. 2014;47(1):1-8.

6. Murray MG, Thompson WF. Rapid isolation of high molecular weight plant DNA. Nucleic Acids Res. 1980;8(19):4321-6.

7. Untergasser A, et al. Primer 3-new capabilities and interfaces. Nucleic Acids Res. 2012;40(15):1-12.

8. Schuelke M. An economic method for the fluorescent labeling of PCR fragments. Nat Biotechnol. 2000;18(2):233-4.

9. Yeh F, Rong-cai Y, Boyle T, Freeware MW. POPGENE, the user-friendly shareware for population genetic analysis. Mol Biol Biotechnol. Center, Univ. Alberta, Edmonton, Alberta, Canada, no. August; 1997. p. 1-29.

10. Weir BS, Cockerham CC. Estimating F-statistics for the analysis of population structure. Evolution (N. Y.). 1984:38(6):1358-70.

11. Belkhir K, Borsa P, Chikhi L, Raufaste N, Bonhomme F. Genetix 4.05 Logiciel sous Windows ${ }^{\mathrm{TM}}$ pour la genetique des populations. Montpellier: Université de Montpellier; 2003.

12. Raymond M, Rousset F. GENEPOP (version 1.2): population genetics software for exact tests and ecumenicism. J Hered. 1995;86(3):248-9.

13. Van Oosterhout C, Hutchinson WF, Wills DPM, Shipley P. MICRO-CHECKER: software for identifying and correcting genotyping errors in microsatellite data. Mol Ecol Notes. 2004;4(3):535-8.

\section{Consent for publication}

Not applicable. 